\title{
Electron Microscope Study on Fine Structures of the Austenite in an Ausaged Fe-Ni-Al Alloy*
}

\author{
By Tsugio Tadaki**, Hisakatsu Kawarai***, Yoshiyuki Nakata** \\ and Ken'ichi Shimizu**
}

\begin{abstract}
Fine structures of the austenite in an ausaged $\mathrm{Fe}-28.9 \mathrm{Ni}-5.7 \mathrm{Al}$ (mass \%) alloy have been examined by means of conventional and high resolution transmission electron microscopy and electron diffraction. The ageing treatment was carried out at various temperatures in the range between 673 and $923 \mathrm{~K}$ for up to $2.88 \mathrm{Ms}$, which gave rise to complicated changes in the martensite-start temperature, $M_{s}$, of the alloy. Upon ageing, typically at $823 \mathrm{~K}$, the austenite exhibited characteristic fine structures. That is, the conventional transmission electron micrographs showed striations in them and the corresponding electron diffraction patterns did extra reflections other than the fundamental austenite ones and $\langle 011\rangle^{*}$ diffuse streaks. Detailed observations suggested that these fine structures were due to the formation of coherent precipitates with a $\mathrm{Ll}_{0}$ type ordered structure during ausageing, not with the $\mathrm{Ll}_{2}$ or $\mathrm{DO}_{3}$ type one previously reported. Fine structures were also observed in the grown precipitates themselves on the later stage of ageing, and they were accounted for by the $\mathrm{Ll}_{0}$ type ordered structure. The relation between the complicated variations in $M_{\mathrm{s}}$ and the microstructural change of austenite upon ausageing was well explained.
\end{abstract}

(Received October 20, 1987)

Keywords: ausageing, iron-nickel-aluminum alloy, martensitic transformation, transformation temperature, coherent precipitate, coherency strain, electron microscopy

\section{Introduction}

It has been reported so $\mathrm{far}^{(1)-(9)}$ that in $\mathrm{Fe}-\mathrm{Ni}$ based ternary alloys, such as $\mathrm{Fe}-\mathrm{Ni}-\mathrm{Ti}$ and $\mathrm{Fe}-$ $\mathrm{Ni}-\mathrm{Al}, \gamma^{\prime}$ precipitates with the $\mathrm{Ll}_{2}$ type ordered structure are formed upon ausageing, and that they affect significantly the martensitic transformation occurring in those alloys upon subzero cooling, in respect of the martensite start temperature, $M_{s}$, and the morphology, substructure and crystal structure of martensites. According to previous studies by conventional transmission electron microscopy (CTEM), however, it appears that the precipitation process in those alloys proceed in somewhat

* A part of this paper was originally presented at the Annual Autumn Meetings of the Japan Institute of Metals, Akita and Hiroshima, (1983), (1984).

** The Institute of Scientific and Industrial Research, Osaka University, 8-1, Mihoga-oka, Ibaraki, Osaka 567, Japan.

*** Graduate Student, Osaka University. Present address: Mater. Analys. \& Eval. Cent., Mater. \& Electr. Dev. Lab., Mitsubishi Electric Corporation, 8-1-1, Tsukaguchi-Honmachi, Amagasaki, Hyogo 661, Japan. different manners. That is, spherical precipitates are formed in $\mathrm{Fe}-\mathrm{Ni}-\mathrm{Ti}$ alloys, being evenly distributed in the austenite matrix ${ }^{(4)(6)(9)}$, while cuboid ones are formed in $\mathrm{Fe}-\mathrm{Ni}-\mathrm{Al}$ alloys $^{(1)(3)}$. The austenite in the latter alloys exhibits marked striations along certain directions in CTEM images and also "satellite" reflections in electron diffraction (ED) patterns. Hornbogen and Meyer ${ }^{(1)}$ reported that the satellites approached the respective principal reflections as ageing proceeds, as in spinodally decomposed alloys. Meanwhile, Gun'ko et $a l .{ }^{(3)}$ explained the satellites as a cross-sectional view of diffuse streaks along $\langle 110\rangle^{*}$ directions in reciprocal space cut by the Ewald sphere, and ascribed the origin to coherent shear strains produced by the concurrent formation of another precipitate named $\alpha^{\prime}$ with the $\mathrm{DO}_{3}$ type ordered structure. Ausageing effects in the former $\mathrm{Fe}-\mathrm{Ni}-\mathrm{Ti}$ alloys have so far been examined in some detail ${ }^{(4)-(9)}$, but those in the latter $\mathrm{Fe}-\mathrm{Ni}-\mathrm{Al}$ alloys have not so much $^{(1)-(3)}$. Hence, the nature of the diffuse streaks and the corresponding striations in the austenite of the latter alloys have not been well understood yet. Moreover, microstructural 
changes of the austenite upon ausageing have not been explored in connection with the complicated variations in $M_{\mathrm{s}}$, as previously reported $^{(2)}$. Therefore, the present investigation has been conducted in order to clarify those obscure points by means of CTEM and high resolution electron microscopy (HREM). The results obtained will be reported in this paper.

\section{Experimental Procedure}

An alloy ingot with a nominal composition of $\mathrm{Fe}-29 \mathrm{Ni}-6 \mathrm{Al}$ (mass\%) was made by induction-melting electrolytic iron (99.9\%), Mond nickel $(99.97 \%)$ and high purity aluminum $(99.99 \%)$ in argon atmosphere, and by casting the melt into an iron mould. Chemical analysis of the ingot showed the composition to be $\mathrm{Fe}-28.9 \mathrm{Ni}-5.7 \mathrm{Al}$ (mass\%), which was roughly the same as those of the alloys previously studied $^{(1)(2)}$. After being hot-forged, the ingot was homogenized at $1473 \mathrm{~K}$ for $86.4 \mathrm{ks}$ in an evacuated quartz tube, and then hot- and coldrolled to a sheet of $0.3 \mathrm{~mm}$ in thickness, from which specimens with suitable sizes were cut for the electrical resistivity vs temperature measurement to determine $M_{\mathrm{s}}$ and for CTEM and HREM observations. All the specimens were solution-treated at $1473 \mathrm{~K}$ for $7.2 \mathrm{ks}$ in evacuated quartz tubes and then quenched into iced water. Subsequently, a variety of ageing treatments were carried out at various temperatures in the range from 673 to $923 \mathrm{~K}$ for various periods up to $2.88 \mathrm{Ms}$ in sealed quartz tubes back filled with argon.

CTEM and HREM observations were made at room temperature by using of electron microscopes of the HU-650 and H-700SS types. The former operating at $500 \mathrm{kV}$ was used for the CTEM observation, and the latter at $200 \mathrm{kV}$, for the HREM observation.

\section{Results}

\section{Change in $M_{\mathrm{s}}$ upon ausageing}

$M_{\mathrm{s}}$ of the present alloy was about $210 \mathrm{~K}$ in the as-quenched state, but it varied in a complicated manner with ausageing, depending on

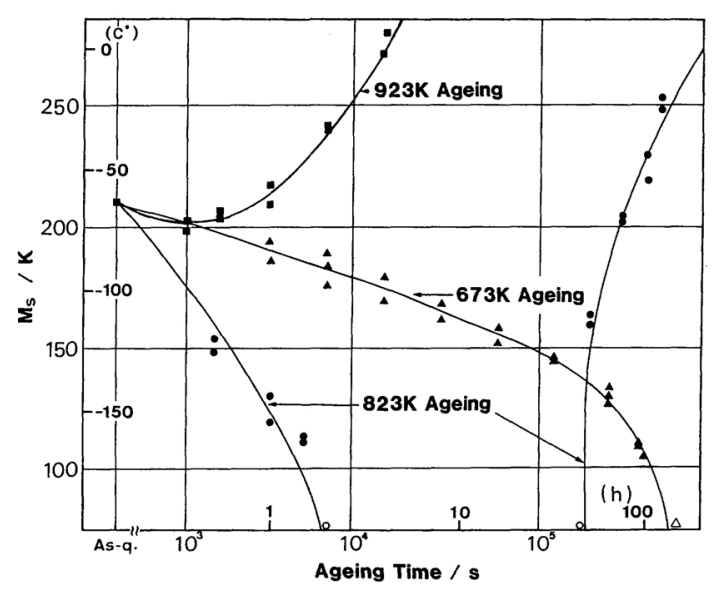

Fig. 1 Change in the $M_{\mathrm{s}}$ temperature of an $\mathrm{Fe}-28.9 \mathrm{Ni}-$ $5.7 \mathrm{Al}$ (mass\%) alloy upon ausageing at various temperatures as indicated in the figure. Plotted as a function of ageing time. Open symbols mean that $M_{\mathrm{s}}$ is below $77 \mathrm{~K}$.

temperature and time of the ausageing, as shown in Fig. 1. $M_{\mathrm{s}}$ is raised by ageing at 923 $\mathrm{K}$, but it is depressed once below $77 \mathrm{~K}$ and then raised again above that temperature after a certain period by ageing at $823 \mathrm{~K}$. Upon ageing at $673 \mathrm{~K}$, however, it remains below $77 \mathrm{~K}$ even after $2.88 \mathrm{Ms}$. The overall feature of the variations in $M_{\mathrm{s}}$ of the present ausaged alloy is thus consistent with that of the previous reports ${ }^{(1)(2)}$.

\section{Microstructural change in CTEM image}

Figure 2(a) and (b) show a CTEM image of the austenite in an as-quenched specimen and the corresponding ED pattern, respectively. The austenite in the as-quenched state appears to be of a homogeneous solid solution.

Figure 3(a) and (b) show a CTEM image and the corresponding ED pattern, respectively, of the austenite in a specimen subjected to ageing at $823 \mathrm{~K}$ for $3.6 \mathrm{ks}$, by which $M_{\mathrm{s}}$ was lowered down to about $125 \mathrm{~K}$, as seen from Fig. 1. The microstructure of the aged austenite, (a), does not appear much different from that in Fig. 2(a). However, in Fig. 3(b), some extra reflections are recognised besides the fundamental austenite ones. The extra reflections have so far been interpreted as superlattice ones of coherent $\gamma^{\prime}-\mathrm{Ni}_{3} \mathrm{Al}$ precipitates with the $\mathrm{Ll}_{2}$ type ordered structure, which are formed upon ausageing ${ }^{(1)(3)}$. In fact, the appearance of those extra reflections in various orientations of 

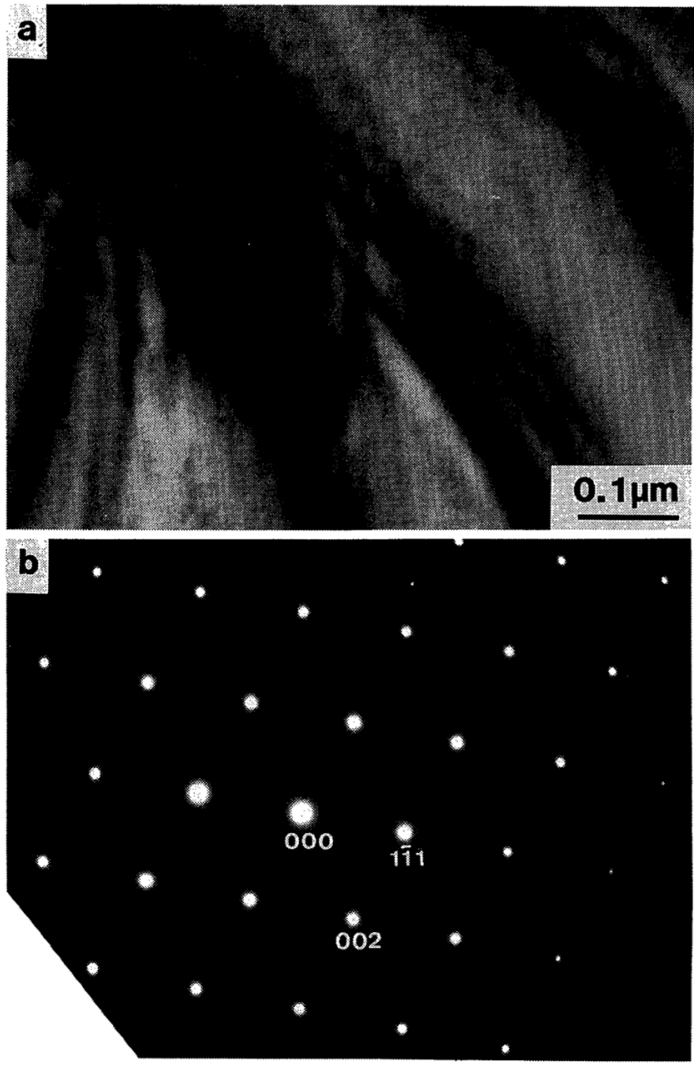

Fig. 2 CTEM image (a) and the corresponding ED pattern (b) of the austenite in an as-quenched specimen, showing that the austenite is almost of a homogeneous solid solution.

austenite was apparently consistent with that from the $\mathrm{Ll}_{2}$ ordered structure. Then, the reflections from the precipitates would be indexed, by referring to the FCC lattice. However, close examination on other fine structures associated with the formation of the precipitates, which will be shown later, suggests that the precipitates possess the $\mathrm{Ll}_{0}$ type ordered structure, as will be discussed in detail later.

In Fig. 3(b), besides the extra reflections, are noted spike-like diffuse streaks around the fundamental austenite reflections, especially those off the Bragg positions in the $\{011\}$ orientation. It is thus seen that the diffuse streaks do not exist in the exact $\{011\}$ orientations. The direction along which the diffuse streaks are observed will be examined later.

Figure 4(a) is a CTEM image of the austenite in a specimen ausaged at $823 \mathrm{~K}$ for $90 \mathrm{ks}$. It is
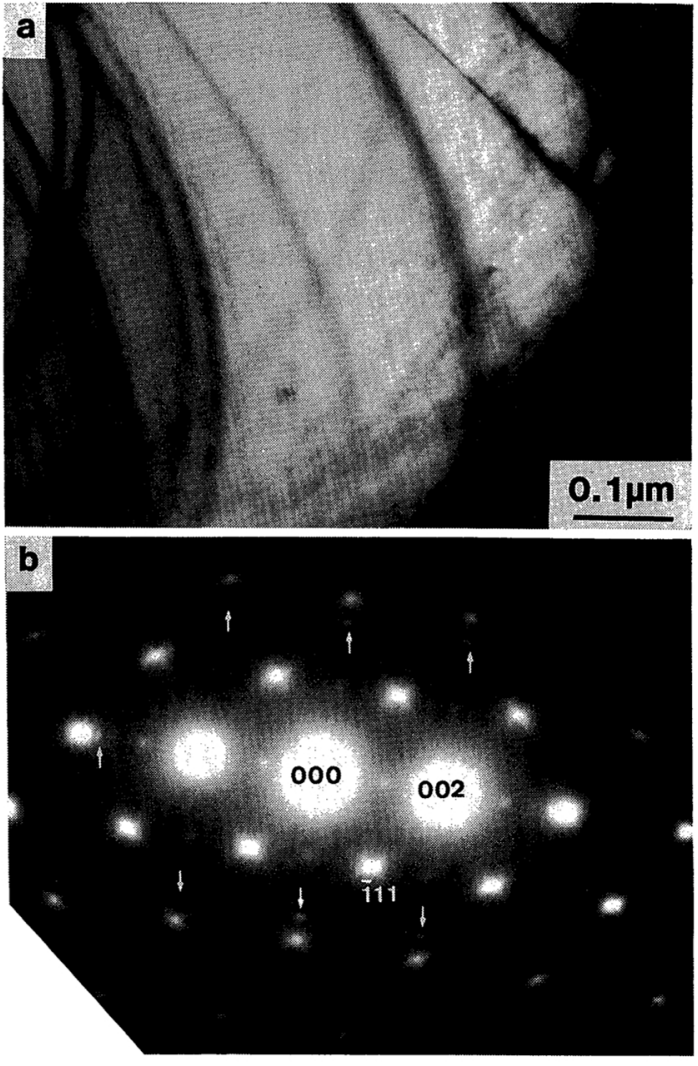

Fig. 3 CTEM image (a) and the corresponding ED pattern (b) of the austenite in a specimen aged at $823 \mathrm{~K}$ for $3.6 \mathrm{ks}$. Note some extra reflections (not the set of arrowed ones from a surface film) other than the fundamental austenite ones and also spike-like diffuse scattering around the austenite ones.

to be noted here that the austenite exhibits a characteristic substructure, i.e., marked striations. Such a substructure has already been observed $^{(1)(3)}$, but its crystallographic properties have not been examined in detail yet. In the present study, they were explored by the trace analysis, using several CTEM images with different orientations. As a result, it was found that the striations were parallel to the $\{011\}$ plane traces. Hence, it is seen in (a), which is of nearly the $\{011\}$ orientation, that the striations are parallel to the $\langle 111\rangle$ directions. Figure 4(b) shows an ED pattern corresponding to (a), and it is a little deviated from one of the $\{011\}$ orientations around the $\langle 001\rangle^{*}$ direction. To be noted here is that satellite-like reflections appear around the austenite reflections off 

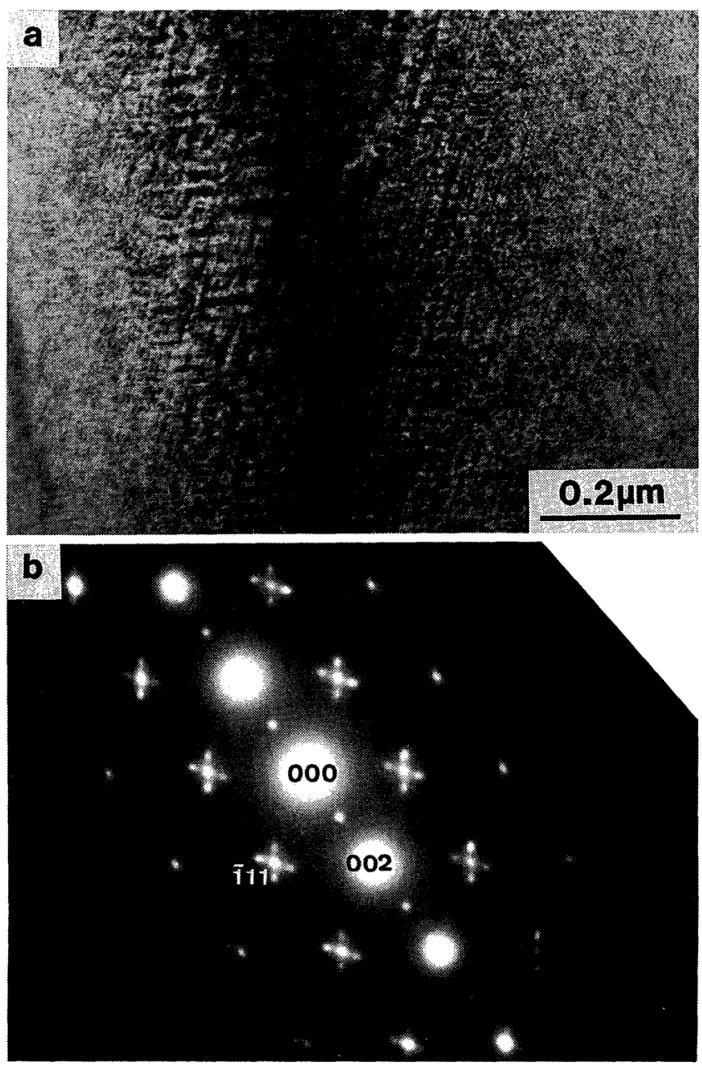

Fig. 4 CTEM image (a) and the corresponding ED pattern (b) of the austenite in a specimen aged at $823 \mathrm{~K}$ for $90 \mathrm{ks}$. Note the severely striated substructure along $\langle 111\rangle$ directions in (a) and also "satellite reflections" appearing along $\langle 112\rangle^{*}$ directions in (b). See the text for detail.

their Bragg positions. Since substantially no satellites are visible around the systematic reflections along the $\langle 001\rangle^{*}$ direction, it is seen that the satellites are a cross-sectional view of streaks cut by the Ewald sphere. Moreover, it is seen in (b) that the satellites appear along the $\langle 112\rangle^{*}$ directions which are perpendicular to the striations along the $\langle 111\rangle$ directions in the corresponding CTEM image of (a). These observations indicate that the diffuse streaks run along the $\langle 011\rangle^{*}$ directions. In fact, the appearance of the diffuse streaks in various orientations may be explained by the $\langle 011\rangle^{*}$ streaks. This result is consistent with that by Gun'ko et al. ${ }^{(3)}$

Figure 5(a) shows a CTEM image of the austenite in a specimen subjected to ageing at
$823 \mathrm{~K}$ for $263 \mathrm{ks}$, by which $M_{\mathrm{s}}$ was raised up above $77 \mathrm{~K}$ again, i.e., about $160 \mathrm{~K}$. The striated substructure of the austenite is similar to that shown in Fig. 4(a). Figure 5(b) shows the corresponding ED pattern nearly in the $\langle 110\rangle$ orientation, where the austenite reflections along the $\langle 110\rangle^{*}$ direction are strongly excited. Here, it is interesting to note that the streaks are absent along the specific $\langle 110\rangle^{*}$ direction. This suggests that the appearance of the $\langle 110\rangle^{*}$ streaks obeys an extinction rule analogous to that for thermal diffuse scattering due to transverse acoustic phonons of the $\langle 011\rangle^{*}\langle 01 \overline{1}\rangle \operatorname{mode}^{(10)}$. If this is the case, the $\langle 011\rangle^{*}$ streaks in the ED patterns and the corresponding striations in the CTEM images indicate that there exist $\{011\}\langle 01 \overline{1}\rangle$ static shear strains in the austenite matrix.

Figure 5(c) shows a dark field CTEM image formed by an 110 type superlattice reflection of precipitate, which is encircled in (b). It is seen in (c) that the precipitates are still extremely fine, i.e., only a few $\mathrm{nm}$ in size, and that they are evenly distributed in the austenite matrix.

CTEM images taken from the austenite of a $923 \mathrm{~K}$-aged specimen exhibited similar substructures to those shown in Figs. 4 and 5, when the ageing time was limited less than roughly $3.6 \mathrm{ks}$. The prolonged ageing, however, brought about a different microstructure. Figure 6 shows an example of the CTEM images, which was obtained from the austenite aged at $923 \mathrm{~K}$ for $54 \mathrm{ks}$. As seen in (a), the precipitates grew a little larger to form a rodlike morphology, elongating along the $\langle 001\rangle$ directions of precipitate. The corresponding ED pattern shown in (b) consists of two sets of reflections, one being from the precipitate and the other from a BCC phase, as indexed. The BCC phase is supposed to be the martensite, judging from the rise in $M_{\mathrm{s}}$ with ageing, as shown in Fig. 1. Here, it is to be noted that the reflections from the precipitates are still accompanied by the $\langle 011\rangle^{*}$ streaks in spite of the fact that the matrix phase for the precipitates has changed from austenite to martensite. This indicates that the origin of the $\langle 011\rangle^{*}$ streaks still exists in the precipitates themselves. It is further to be noted in (b) that the 002 reflection of precipitate makes doublets. On the other 

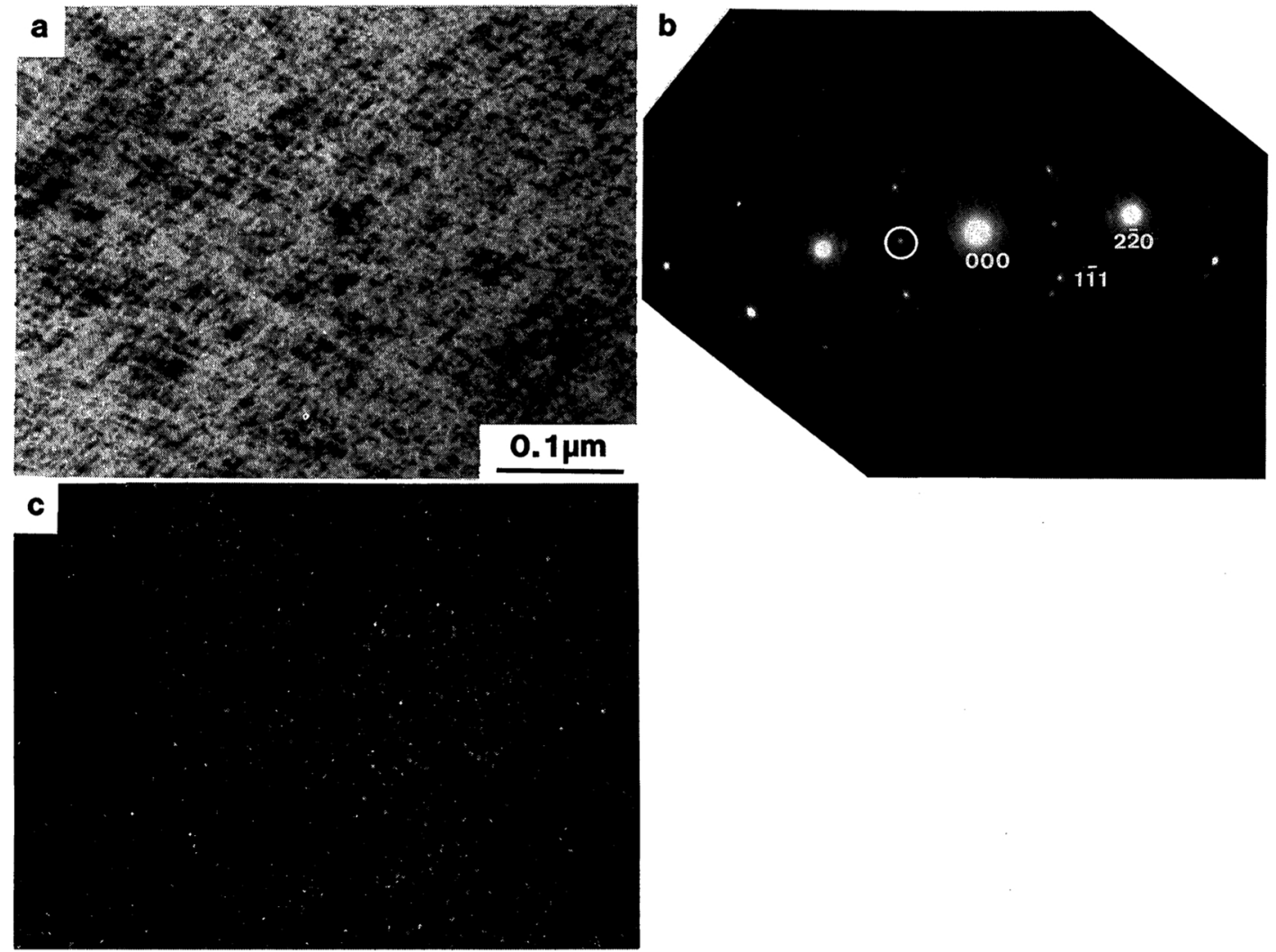

Fig. 5 Bright field CTEM image (a) of the austenite in a specimen aged at $823 \mathrm{~K}$ for $263 \mathrm{ks}$, the corresponding ED pattern (b) and dark field CTEM image formed by an 110 type (encircled in (b)) reflection of precipitate $(\mathrm{c})$. Note the absence of the $\langle 011\rangle^{*}$ streaks along particular $\langle 110\rangle^{*}$ directions in (b), and also the extremely fine precipitates, a few $\mathrm{nm}$ in size, evenly distributed in the austenite matrix in (c).

hand, (c) is a dark field CTEM image from the area identical to (a), which was formed by a 001 type reflection of precipitate. It appears that the rod-like precipitates consist of fine segments with different orientations, the segments being roughly several $\mathrm{nm}$ in size. These fine structures in the grown precipitates will be discussed later in terms of the ordered structure of the precipitates.

\section{Microstructure observed by HREM}

Figure $7(\mathrm{a})$ is a lattice image by HREM of the austenite in a specimen as-quenched, which was formed with the transmitted and 111 diffracted beams in the $\langle 211\rangle$ orientation. The spacing of the lattice fringes corresponds to $0.21 \mathrm{~nm}$ of $\{111\}$ planes (lattice parameter of the as-quenched austenite was determined by $\mathrm{X}$-ray diffraction to be $0.36 \mathrm{~nm}$ ). To be noted here is that the lattice fringes are a little wavy, suggesting that the austenite lattice is distorted locally. However, since no extra reflections indicative of the formation of precipitates are observed in the as-quenched state, as mentioned before, the local lattice distortion is supposed to be due to the presence of solute atom clusters, which are possibly less than $2 \mathrm{~nm}$ in size.

The lattice image shown in Fig. 7(b) is of the austenite in a specimen aged at $673 \mathrm{~K}$ for 263 $\mathrm{ks}$, which was formed by the transmitted and three $\overline{1} 1 \overline{1}, \overline{1} 11$ and 002 diffracted beams. The austenite thus aged exhibits substantially the same substructures and diffraction effects as 

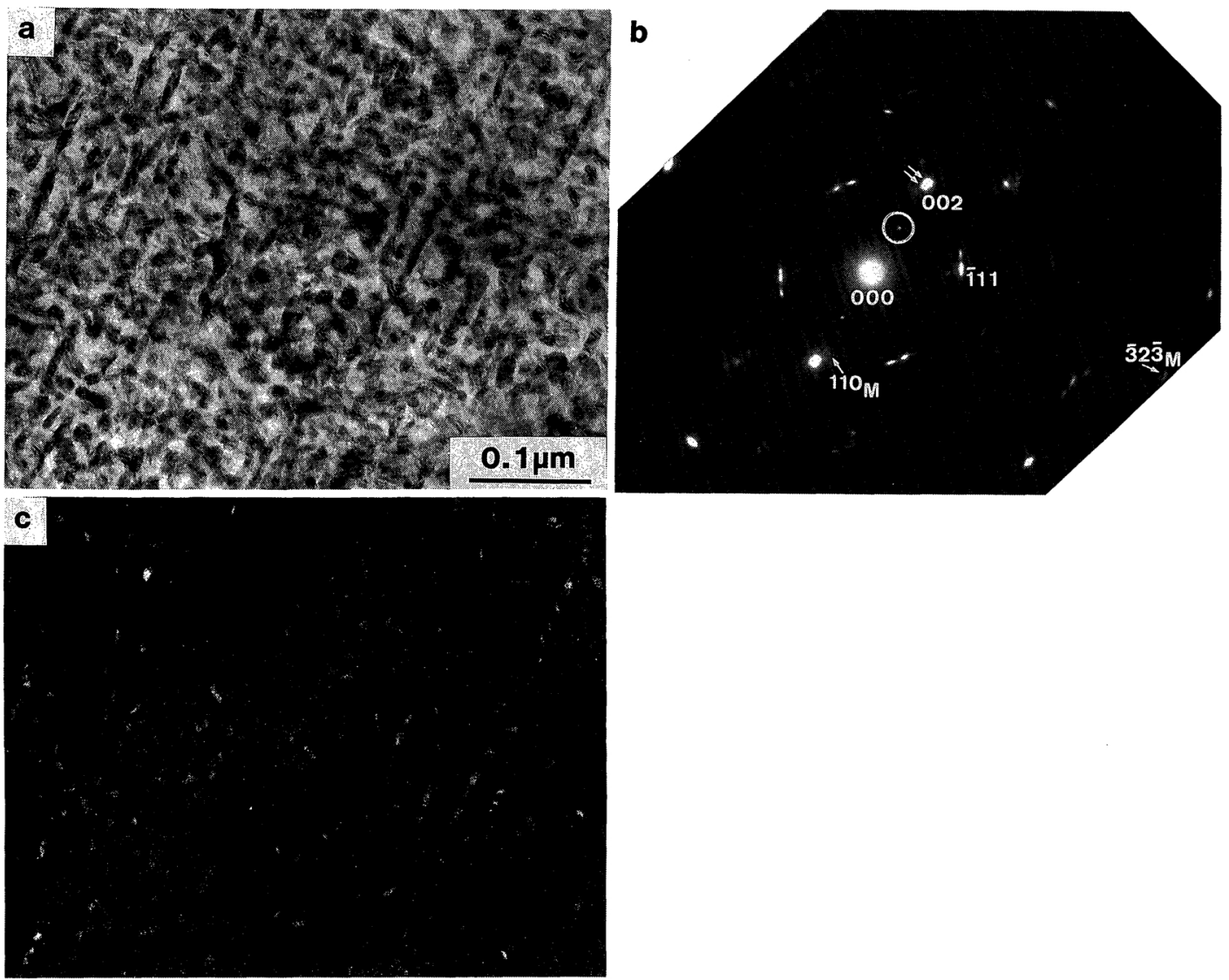

Fig. 6 Bright field CTEM image of a specimen aged at $923 \mathrm{~K}$ for $54 \mathrm{ks}$ (a), the corresponding ED pattern (b) and dark field CTEM image formed by a 001 type (encircled in (b)) reflection of precipitate (c).

those shown in Fig. 3. Hence, strain contrasts visible in (b) are supposed to be due to the existence of precipitates, which are still possibly less than $2 \mathrm{~nm}$ in size.

Figure 7(c) shows another lattice image of the austenite in a specimen aged at $923 \mathrm{~K}$ for $1.8 \mathrm{ks}$ in the $\langle 110\rangle$ orientation, the fringes corresponding to the $\{111\}$ planes of austenite. The CTEM images and the corresponding ED patterns of the austenite thus aged were apparently similar to those shown in Fig. 5. Here are observed regions with darker contrasts, which are elongated along the $\langle 111\rangle$ direction and are roughly $2.5 \mathrm{~nm}$ wide and $5 \mathrm{~nm}$ long. The darker contrasts appear to correspond to the precipitates. Since the $\langle 111\rangle$ directions are parallel to the $\{011\}$ plane traces in the $\langle 110\rangle$ orientation, the lattice image in (c) probably indicates that the precipitates form preferentially on the $\{011\}$ planes of austenite.

\section{Discussion}

\section{Crystal structure of the precipitate}

The precipitates formed in the ausaged $\mathrm{Fe}$ $\mathrm{Ni}-\mathrm{Al}$ alloys have so far been reported to be of the $\gamma^{\prime}-\mathrm{Ni}_{3} \mathrm{Al}$ phase with the $\mathrm{Ll}_{2}$ type ordered structure $^{(1)(3)}$, like $\gamma^{\prime}-\mathrm{Ni}_{3} \mathrm{Ti}$ precipitates in $\mathrm{Fe}-$ $\mathrm{Ni}-\mathrm{Ti}$ alloys ${ }^{(4)}$. In fact, the superlattice reflections observed in ED patterns of the present ausaged $\mathrm{Fe}-\mathrm{Ni}-\mathrm{Al}$ alloy were apparently consistent with those from the $\mathrm{Ll}_{2}$ type precipitate. However, if this were true, isotropic volume 

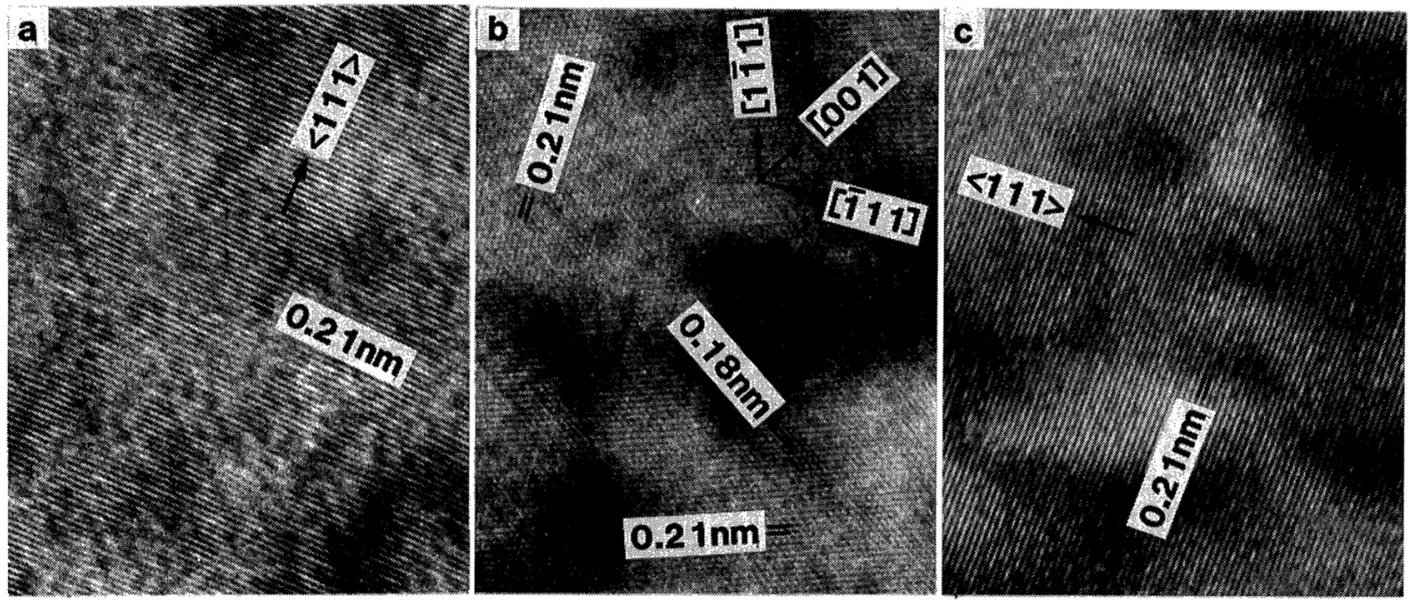

Fig. 7 Lattice images of the austenite in the specimen as-quenched (a), aged at $673 \mathrm{~K}$ for $263 \mathrm{ks}$ (b) and aged at $923 \mathrm{~K}$ for $1.8 \mathrm{ks}(\mathrm{c})$.

strains due to the difference in lattice parameter between the precipitate and the austenite would be produced, and a mottled structure would be observed in CTEM images of the austenite, as actually observed in $\mathrm{Fe}-\mathrm{Ni}$ Ti alloys ${ }^{(4)(6)}$. Furthermore, it has been shown that the volume strains cause diffuse scattering along the radial directions in reciprocal space around the austenite reflections ${ }^{(11)}$, as observed also in Fe-Ni-Ti alloys by X-ray diffraction ${ }^{(7)}$. However, unlike the $\mathrm{Fe}-\mathrm{Ni}$-Ti alloys, the present $\mathrm{Fe}-\mathrm{Ni}-\mathrm{Al}$ alloy exhibited marked striations along $\{011\}$ plane traces in the CTEM images and strong $\langle 011\rangle^{*}$ streaks in the corresponding ED patterns, as shown in the preceding section. These facts, together with the extinction rule observed for the $\langle 011\rangle^{*}$ streaks, indicate that $\{011\}\langle 01 \overline{1}\rangle$ shear strains exist in the austenite lattice of the present ausaged $\mathrm{Fe}-\mathrm{Ni}-\mathrm{Al}$ alloy, and therefore that the coherent precipitates in the alloy must produce the shear strains. Gun'ko et al. ${ }^{(3)}$ reached the same conclusion, and proposed a $\mathrm{DO}_{3}$ type ordered structure for the coherent precipitates. However, this is not the case in the present alloy, because no superlattice reflections indicative of the formation of $\mathrm{DO}_{3}$ type precipitates were observed in the ED patterns obtained, and furthermore the $\mathrm{DO}_{3}$ precipitate does not seem to produce the shear strains, because of cubic symmetry. It is thus conceivable that the coherent precipitates in the present alloy take a $\mathrm{Ll}_{0}$ type ordered structure, because the $\mathrm{Ll}_{0}$ structure is of the tetragonal symmetry, as explained below.

If the coherent $\mathrm{Ll}_{0}$ type precipitates are formed in the austenite matrix, tetragonal coherency strains are built up around the precipitates along the $\langle 001\rangle$ directions of austenite. The tetragonal coherency strains are able to be relaxed by $\{011\}\langle 01 \overline{1}\rangle$ shears, because this is energetically favorable if the anisotropy factor of the austenite lattice is larger than unity. Such a relaxation of the tetragonal coherency strains probably occur and leave the shear strains in the present ausaged $\mathrm{Fe}-\mathrm{Ni}-\mathrm{Al}$ alloy, since the anisotropy factor of $\mathrm{Fe}-\mathrm{Ni}$ binary alloys undergoing a martensitic transformation has been known to be about $5^{(12)}$.

By the way, when the $\mathrm{Ll}_{0}$ type ordered precipitates are coherently formed in a FCC matrix, their ED patterns are indistinguishable from those of the $\mathrm{Ll}_{2}$ type ordered ones, so far as the appearance of superlattice reflections is concerned, as mentioned in the preceding section. Such an example is found also in the early stage of ordering in $\mathrm{Cu}-\mathrm{Au}$ alloys ${ }^{(13)}$. In the $\mathrm{Cu}-\mathrm{Au}$ alloys, $\mathrm{Ll}_{0}$ type $\mathrm{CuAu}(\mathrm{I})$ ordered domains are coherently formed, and striations parallel to $\{011\}$ planes are observed in the disordered FCC matrix, as in the present alloy. Furthermore, the $\mathrm{Ll}_{0}$ ordered domains are observed to nucleate on the $\{011\}$ planes of the 
disordered matrix ${ }^{(14)}$. This is also very similar to the present observation that the coherent precipitates are formed on $\{011\}$ planes of the ausaged matrix (see Fig. 7(c)).

The tetragonal coherency strains along the $\langle 001\rangle$ directions of austenite are considered to increase, as the precipitates grow larger, and eventually the tetragonal coherency is lost. In fact, the precipitates shown in Fig. 6(a) appear to become incoherent with the matrix, because they have grown and moreover the matrix has become the BCC phase. It is thus considered that the split 002 reflections of the precipitates seen in Fig. 6(b) correspond to the 002 and 200 ones of the tetragonal $\mathrm{Ll}_{0}$ type ordered $(\mathrm{Ni}, \mathrm{Fe})$ $\mathrm{Al}$ phase. The bright regions seen in the dark field CTEM image of Fig. 6(c) clearly suggest that the largely grown precipitates consist of fine twins on the $\{011\}$ planes. Such fine twins cause $\langle 011\rangle^{*}$ streaks around reflections from the precipitates, as actually observed in Fig. 6(b). These are consistent with the $\mathrm{Ll}_{0}$ type ordered structure of the precipitates.

The $\mathrm{Ll}_{0}$ type $(\mathrm{Ni}, \mathrm{Fe}) \mathrm{Al}$ phase does not exist as a thermal equilibrium phase ${ }^{(15)}$. However, it possibly exist as an intermediate phase, like the $\mathrm{Ll}_{2}$ type $\gamma^{\prime}-\mathrm{Ni}_{3} \mathrm{Ti}$ phase in $\mathrm{Fe}-\mathrm{Ni}-\mathrm{Ti}$ alloys, in which the thermal equilibrium phase with the composition of $\mathrm{Ni}_{3} \mathrm{Ti}$ is of the $\mathrm{DO}_{24}$ type $^{(16)}$. It is thus reasonable to conclude that the coherent precipitates formed in the present ausaged $\mathrm{Fe}$ $\mathrm{Ni}-\mathrm{Al}$ alloy possess the $\mathrm{Ll}_{0}$ type ordered structure.

\section{Relation between the change in $M_{s}$ and the microstructure of austenite}

In the early stage of ageing at 823 and $673 \mathrm{~K}$, $M_{\mathrm{s}}$ was depressed markedly as seen in Fig. 1 . Meanwhile, the ED patterns taken at this stage exhibit superlattice reflections indicative of the formation of $\mathrm{Ll}_{0}$ type precipitates in the austenite. But the precipitates are so fine that the tetragonal coherency strains built up around them are very small. Hence, the relaxation in the austenite by $\{011\}\langle 01 \overline{1}\rangle$ shears does not take place predominantly. In fact, striations along $\{011\}$ plane traces were hardly observed in the CTEM images of austenite at this stage. However, the fine precipitates are considered to be highly coherent with the austenite lattice, and so the martensitic transformation is suppressed by their existence to a great extent, because extra energy is needed so as for the precipitates to transform together with the matrix. This is believed to be the reason for the marked depression of $M_{\mathrm{s}}$ at this stage.

With further ageing, the precipitates grow larger, and consequently the tetragonal coherency strains are expected to increase. Thus, the strain relaxation by $\{011\}\langle 01 \overline{1}\rangle$ shear becomes predominant, resulting in marked striations in CTEM images of the austenite matrix. The strain relaxation is supposed to make the precipitates semicoherent or incoherent with the austenite matrix. Such precipitates become ineffective in supressing the martensitic transformation. Concurrently, the growth of precipitates causes a depletion of solute concentration in the austenite matrix. Therefore, $M_{\mathrm{s}}$ is expected to be raised again, as actually observed. The reason for the increase of $M_{\mathrm{s}}$ upon ageing at $923 \mathrm{~K}$ is considered in the same way as above.

\section{Conclusions}

Fine structures of the austenite in an ausaged $\mathrm{Fe}-\mathrm{Ni}-\mathrm{Al}$ alloy, which are associated with complicated changes of $M_{\mathrm{s}}$ upon ausageing, have been explored by CTEM and HREM. The main results obtained are as follows:

(1) The salient striations observed in the CTEM images of austenite, typically at $823 \mathrm{~K}$, were parallel to $\{011\}$ plane traces. The strong $\langle 011\rangle^{*}$ streaks observed in the corresponding ED patterns seemed to appear with an extinction rule analogous to that for thermal diffuse scattering due to transverse acoustic phonons of $\langle 011\rangle^{*}\langle 01 \overline{1}\rangle$ mode. These observations indicate that $\{011\}\langle 01 \overline{1}\rangle$ shear strains exist in the austenite lattice.

(2) The generation of the shear strains was well accounted for by assuming that the precipitates formed in the ausaged alloy possess a $\mathrm{Ll}_{0}$ type ordered structure, not the $\mathrm{Ll}_{2}$ type one reported so far. The assumption was consistent with the observed fine structures in the austenite and the precipitate itself.

(3) The decrease in $M_{s}$, as observed in the 
early stage of ageing at 673 and $823 \mathrm{~K}$, was ascribed to the formation of the fine precipitates coherent with the austenite lattice. On the other hand, the increase in $M_{\mathrm{s}}$, as observed in the later stage of ageing at 823 and $923 \mathrm{~K}$, was ascribed to the coherency loss due to the relaxation of the coherent strains, which increase with the size of precipitates, by $\{011\}\langle 01 \overline{1}\rangle$ shears, and to some depletion of solute atoms in the austenite matrix accompanying the growth of precipitates.

\section{Acknowledgements}

The authors appreciate a useful discussion with Professor $\mathrm{H}$. Chen at University of Illinois. The present work was partly supported by the Grant-in-Aid for Fundamental Scientific Research (Ippan A, 1980-81, and Ippan B, 1985-86) from the Ministry of Education, Science and Culture, Japan.

\section{REFERENCES}

(1) E. Hornbogen and W. Meyer: Z. Metallk., 58 (1967), 372.

(2) E. Hornbogen and W. Meyer: Acta Metall., 15 (1967), 584.
(3) L. P. Gun'ko, V. V. Kokorin and K. V. Chuistov: Fiz. metal. metalloved., 43 (1977), 427.

(4) J. K. Abraham and J. S. Pascover: Trans. Met. Soc. AIME, 245 (1969), 759.

(5) L. I. Lysak, S. P. Kondrat'yev and V. S. Tatarchuk: Fiz. metal. metalloved., 42 (1976), 344.

(6) T. Maki and C. M. Wayman: Acta Metall., 25 (1977), 695.

(7) M. M. Hall, P. G. Winchell and P. Guy: Acta Metall., 25 (1977), 735.

(8) M. Hayakawa and M. Oka: Reports of the Faculty of Engineering, Tottori Univ., 11 (1980), 20.

(9) T. Tadaki, K. Asayama and K. Shimizu: Trans. JIM, 25 (1984), 80.

(10) K. Otsuka, C. M. Wayman and H. Kubo: Met. Trans., 9A (1978), 1075.

(11) A. G. Khachaturyan and M. P. Usikov: Phys. Status Solidi, 23 (1967), 745.

(12) G. Hausch and H. Warlimont: Acta Metall., 21 (1973), 401.

(13) G. Van Tendeloo, S. Amelinckx, S. J. Jeng and C. M. Wayman: J. Mater. Sci., 21 (1986), 4395.

(14) M. Hirabayashi and S. Weissmann: Acta Metall., 10 (1962), 25.

(15) Binary Alloy Phase Diagram, ed. by T. B. Massalski, ASM (1986), Vol. 1, p. 140.

(16) Constitution of Binary Alloys, ed. by M. Hansen, McGraw Hill Book Company, Inc., New York, (1958), p. 1049. 